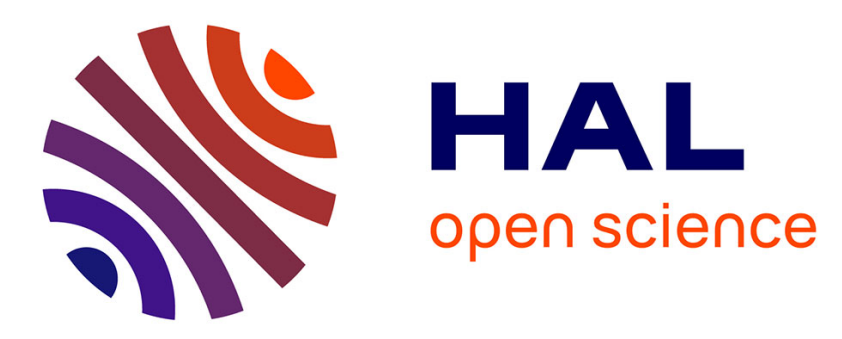

\title{
VRP algorithms for decision support systems to evaluate collaborative urban freight transport systems
}

Jesus Gonzalez-Feliu, Josep-Maria Salanova Grau

\section{To cite this version:}

Jesus Gonzalez-Feliu, Josep-Maria Salanova Grau. VRP algorithms for decision support systems to evaluate collaborative urban freight transport systems. Lauras, M.; Zelm, M.; Archimède, B.; Bénaben, F.; Doumeignts, G. Enterprise Interoperability: I-ESA'14, ISTE-WILEY, pp.196-201, 2015. halshs-00986648

\section{HAL Id: halshs-00986648 \\ https://shs.hal.science/halshs-00986648}

Submitted on 3 May 2014

HAL is a multi-disciplinary open access archive for the deposit and dissemination of scientific research documents, whether they are published or not. The documents may come from teaching and research institutions in France or abroad, or from public or private research centers.
L'archive ouverte pluridisciplinaire HAL, est destinée au dépôt et à la diffusion de documents scientifiques de niveau recherche, publiés ou non, émanant des établissements d'enseignement et de recherche français ou étrangers, des laboratoires publics ou privés. 


\title{
VRP algorithms for decision support systems to evaluate collaborative urban freight transport systems
}

\author{
Jesus Gonzalez-Feliu ${ }^{1}$, Josep-Maria Salanova Grau² \\ ${ }^{1}$ Centre National de la Recherche Scientifique \\ ISH 14 Avenue Berthelot \\ 69363 Lyon Cedex 07 \\ France \\ jesus.gonzalez-feliu@cnrs.fr \\ ${ }^{2}$ Hellenic Institute of Transport, CERTH \\ 6th km Charilaou - Thermi Rd., P.O.Box: 60361 \\ 57001, Thermi, Thessaloniki \\ Greece \\ jose@certh.gr
}

\begin{abstract}
This paper proposes a comparison between genetic and semi-greedy algorithms for a collaborative VRP in city logistics. In order to compare the performance of both algorithms on real-size test cases, we develop a clusterfirst route second algorithm. The clustering phase is made by a seep algorithm, which defines the number of used vehicles and assigns a set of customers to it. Then, for each vehicle, we build a min-cost route by two methods. The first is a semi-greedy algorithm. The second is a genetic algorithm. We test both approaches on real-size instances Computational results are presented and discussed.
\end{abstract}

\section{Résumé}

Cet article propose une comparaison entre algorithmes génétiques et semi-greedy pour un problème de tournées de véhicules collaboratif en logistique urbaine. Pour comparer les deux algorithmes, nous proposons des algorithmes séquentiels basés sur la même phase initiale, puis les tournées sont construites par des procédures différentes. La première est de type sem-greedy; la deuxième un algorithme génétique. Des résultats sont presents et discutés.

Keywords: city logistics systems, two-echelon vehicle routing, cross-docking, simulation, collaboration.

Mots-clé: systèmes de logistique urbaine, problèmes de tournées de véhicules à deux niveaux, cross-docking, simulation, consolidation. 


\section{Introduction}

Vehicle routing (VRP) optimization is a popular research subject, where several soft computing-based meta-heuristic methods have been proposed (Golden et al., 2008). One of the main application fields is city logistics, as we observe three main categories of problems: (1) vehicle routing with time windows, related to accessing city centers, (2) dynamic vehicle routing problems, which take into account variable travel times, and (3) two-echelon vehicle routing, that takes into account ruptures of charge. Although very advanced techniques and algorithms are often proposed in literature, they remain still used in academic cases not always related to real practices.

On the other hand, collaborative transport is being a main issue for researchers and practitioners, but no simulation and optimization tools are available (Gonzalez-Feliu and Morana, 2011). Furthermore, the existing heuristics do not allow to analyse collaborative transport route optimization, since they are related to a single carrier. Collaboration in transport can take several forms (Gonzalez-et al., 2013). Moreover, if we observe the algorithms developed for multi-echelon vehicle routing optimization in city logistics (see Mancini et al., 2014 for a detailed review), we observe that only few of them are applicable to real-life cases, most of which have been developed in the 70's-80's and are fast constructive heuristics.

When two companies want to collaborate, each of them having its two-echelon distribution schema, they will find a common cross-docking point. Then we can state that in partial collaboration a part of the freight to be delivered will be shared then some customers will be visited once (each company will deliver a part of the other company's customers which have in common) and others twice (each company will visit them once). Finally, in a total collaborative approach, each customer is visited once by a company, because they will optimize their transport schemes to divide the geographical area into zones where only one of them will deliver. In this case, the optimization problem presents three main issues:

1. Allocate customers to companies for the last-mile distribution (allocation problem)

2. Locate the most suitable cross-docking points (location-allocation problem)

3. Construct the second-echelon routes (vehicle routing problem)

4. Construct the first-echelon routes (vehicle routing problem) transshipping the freight at the cross-docking facilities in order to load the second-echelon vehicles (matching problem)

This paper aims to propose and compare two fast algorithms for real-life collaborative urban logistics. First, we propose the two algorithms, that follow a sequential structure (cluster-first route-second procedure plus a post-optimization algorithm, the first a semigreedy and the second a genetic algorithm). Second, we test both algorithms on a set of reallife instances and compare them, highlighting the advantages and limits of each procedure.

\section{The proposed algorithms}

In order to compare both algorithms, we propose two clustering-first-route second algorithms which start from the same clustering phase. After that, the route construction and 
the post-optimization heuristics of each algorithm are different. The common clustering procedure is derived from the well-known sweep algorithm (Golden, 1988) and allows to feed each algorithm with the same inputs.

\subsection{Semi-Greedy algorithm}

Given the satellite clusters defined in the first phase, we build routes using a semi-greedy algorithm (Toth and Vigo, 2002). This procedure constructs routes following an iterative procedure that adds each customer to a route. Given iteration i and an uncompleted route, a list of candidates is defined by taking the $n$ closest customers to the last point of the route. This is made by defining a distance threshold $\square$. Customers whom distance to the last point of the route is less than $\square$ are included into the so-called Restricted Candidate List (RCL). Then, the customer inserted on the route is chosen at random from the RCL customers. Finally, the first echelon routes are build following the same principle, knowing the load that will transit on each satellite from the second-echelon routes.

\subsection{Genetic algorithm}

The genetic algorithm is applied to build a near-optimal route from the clustering results. We choose to use a mutation algorithm on single routes because the complexity of the chosen problem applied to real applications needs fast and robust algorithms (Larranaga et al., 1999). The first generation of solutions (tours) is generated randomly to avoid very time-costly procedures. The $i^{\text {th }}$ generation is obtained mutating groups of solutions of the $(i-1)^{\text {th }}$ generation. The possible mutations are the following: flip (reversing the order of the nodes in a sub-route of the solution), swap (interchanging two nodes within the route), and slide (a subroute of the solution goes).

\begin{tabular}{|c|c|c|c|c|c|c|c|c|c|c|c|}
\hline E & F & G & H & I & J & K & L & M & N & O & P \\
\hline E & F & G & N & M & L & K & J & I & H & O & P \\
\hline
\end{tabular}

\begin{tabular}{|c|c|c|c|c|c|c|c|c|c|c|c|}
\hline E & F & G & H & I & J & K & L & M & N & O & P \\
\hline E & F & G & N & I & J & K & L & M & H & O & P \\
\hline
\end{tabular}

\begin{tabular}{|c|c|c|c|c|c|c|c|c|c|c|c|}
\hline E & F & G & H & I & J & K & L & M & N & O & P \\
\hline E & F & G & I & J & K & L & M & N & H & O & P \\
\hline
\end{tabular}

Figure 1. Proposed mutations for the Genetic Algorithm

We initialize the algorithm as follows. The initial number of solutions is set to 60 . The number of iterations depends on the number of nodes, with a lower bound of 1000 for small problems, and a higher bound of 10000 for larger problems.

Both algorithms have been programmed in MATLAB 7.9.0 and run in an Intel Duo Core 2 T9300, 2,5GHz and 4 GB RAM.

\section{Computational results}


First, and to assess the suitability of the methods, we applied them to classical 2E-VRP instances (Gonzalez-Feliu, 2008) comparing it to best solutions found (Baldacci et al., 2013). We are aware that those algorithms are not the best for this problem, since they have been adapted to a more complex case and aim to find a suitable solution quickly. The aim of the proposed methods is not to solve an optimization problem but to provide a quick indicator. Moreover, routes obtained with this algorithm follow behavioral patterns that are close to the reality, as it is observed when comparing results of single routes with the route database, in terms of length and travelled distances.

Table 1. Summary of computational results on Gonzalez-Feliu's (2008) instances

\begin{tabular}{|c|c|c|c|c|}
\hline $\begin{array}{c}\text { Group of } \\
\text { instances }\end{array}$ & $\begin{array}{c}\text { Literature } \\
\text { distance }\end{array}$ & $\begin{array}{c}\text { Algorithm } \\
\text { distance }\end{array}$ & Gap & $\begin{array}{c}\text { Computational } \\
\text { time }\end{array}$ \\
\hline 20 customers & 5.59 & 5.17 & $7.60 \%$ & 0.08 \\
\hline 31 customers & 8.98 & 7.89 & $12.19 \%$ & 0.12 \\
\hline 50 customers & 46.91 & 41.86 & $10.77 \%$ & 0.11 \\
\hline
\end{tabular}

After that, we apply both algorithms to specific instances in urban context. Those instances are based on scenarios proposed in Gonzalez-Feliu and Salanova (2012). The first scenario considers no collaboration, so a single VRP (one stage) is defined. Scenarios 2 and 3 propose a first level of collaboration, but based on infrastructures (no freight transport pooling is allowed but all transport carriers use 2E-VRP approaches). Then, scenarios 4 and 5 propose a real transport pooling approach.

\begin{tabular}{|c|c|c|c|c|c|c|c|c|c|c|}
\hline \multirow[b]{2}{*}{ Test } & \multicolumn{4}{|c|}{ Big vehicles (1st stage) } & \multicolumn{4}{|c|}{ Small vehicles (2nd stage) } & \multicolumn{2}{|c|}{$\begin{array}{c}\text { Computational } \\
\text { times (s) }\end{array}$} \\
\hline & Vehicles & $\begin{array}{c}\text { Semi- } \\
\text { greedy }\end{array}$ & Genetic & Gap & Vehicles & $\begin{array}{c}\text { Semi- } \\
\text { greedy }\end{array}$ & Genetic & Gap & $\begin{array}{l}\text { Semi- } \\
\text { greedy }\end{array}$ & Genetic \\
\hline 1.1 & 1 & 88720 & 80477 & $9 \%$ & 0 & 0 & 0 & $0 \%$ & \multirow{5}{*}{0,06} & \multirow{5}{*}{95,18} \\
\hline 1.2 & 2 & 119013 & 101903 & $14 \%$ & 0 & 0 & 0 & $0 \%$ & & \\
\hline 1.3 & 2 & 189732 & 177316 & $7 \%$ & 0 & 0 & 0 & $0 \%$ & & \\
\hline 1.4 & 2 & 124321 & 116321 & $6 \%$ & 0 & 0 & 0 & $0 \%$ & & \\
\hline 1.5 & 2 & 210067 & 203896 & $3 \%$ & 0 & 0 & 0 & $0 \%$ & & \\
\hline 2.1 & 2 & 31550 & 31550 & $0 \%$ & 8 & 143631 & 136466 & $5 \%$ & \multirow{5}{*}{0,08} & \multirow{5}{*}{330,26} \\
\hline 2.2 & 3 & 34560 & 34560 & $0 \%$ & 11 & 224191 & 215530 & $4 \%$ & & \\
\hline 2.3 & 3 & 95593 & 95593 & $0 \%$ & 4 & 112867 & 97761 & $13 \%$ & & \\
\hline 2.4 & 2 & 40829 & 40829 & $0 \%$ & 7 & 170426 & 162786 & $4 \%$ & & \\
\hline 2.5 & 2 & 73787 & 73787 & $0 \%$ & 6 & 162388 & 154993 & $5 \%$ & & \\
\hline 3.1 & 1 & 60975 & 60975 & $0 \%$ & 8 & 166858 & 154070 & $8 \%$ & \multirow{5}{*}{0,15} & \multirow{5}{*}{454,09} \\
\hline 3.2 & 2 & 87760 & 85495 & $3 \%$ & 11 & 237304 & 219030 & $8 \%$ & & \\
\hline 3.3 & 3 & 234348 & 234348 & $0 \%$ & 5 & 116336 & 104120 & $11 \%$ & & \\
\hline 3.4 & 2 & 106665 & 106665 & $0 \%$ & 7 & 142476 & 128300 & $10 \%$ & & \\
\hline 3.5 & 2 & 205976 & 200108 & $3 \%$ & 8 & 140424 & 133850 & $5 \%$ & & \\
\hline 4.1 & 3 & 34560 & 34560 & $0 \%$ & 11 & 224191 & 215530 & $4 \%$ & \multirow{4}{*}{0,09} & \multirow{4}{*}{355,91} \\
\hline 4.2 & 2 & 40829 & 40829 & $0 \%$ & 7 & 170426 & 162786 & $4 \%$ & & \\
\hline 4.3 & 2 & 73787 & 73787 & $0 \%$ & 6 & 162388 & 154993 & $5 \%$ & & \\
\hline 4.4 & 3 & 121694 & 121694 & $0 \%$ & 12 & 207464 & 194274 & $6 \%$ & & \\
\hline 5.0 & 9 & 960847 & 650186 & $32 \%$ & 39 & 1015965 & 518594 & $49 \%$ & 0,00 & 437,93 \\
\hline
\end{tabular}

Table 1. Computational results of both algorithms on proposed realistic instances

The route lengths obtained by the semi-greedy algorithm are in average 5.5\% higher than the routes obtained by the GA. Form Table 2 we can see that the average difference of 
distances in relation to the number of nodes. Due to the low capacity of the smaller trucks, most of the routes $(55 \%)$ have less than 10 nodes, with an average overestimation of $2 \%$. For longer routes, the average overestimation is $10 \%$. In terms of computation time, the semigreedy algorithm has an average time of 0.001 seconds, while the GA needs 5.25 seconds. The computation time grows exponentially with the number of nodes for both algorithms, but the GA has a fix quantity of time of 5 seconds.

Figure 2 shows the solutions of both algorithms for 2 of the routes. We observe that the semi-greedy algorithm overestimates the route distance, but it is much faster than the GA. However, the differences of distances are small even for big routes, so both algorithms are suitable in strategic planning decision support methods.

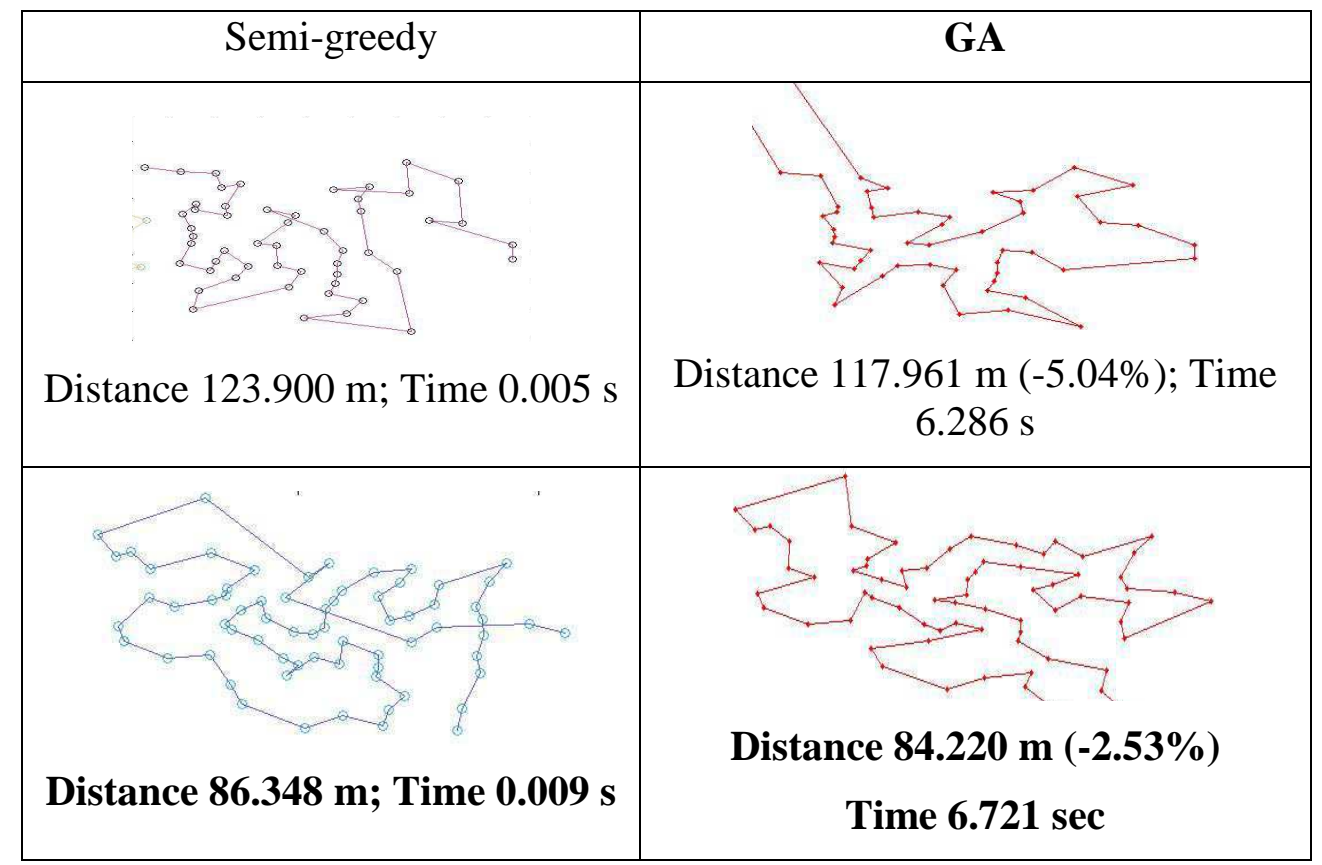

Figure 2. Routes comparison in terms of length and computation time

\section{Conclusion}

The algorithm presented compares the route obtained by a semi-greedy Algorithm with the route obtained by a Genetic Algorithm for the same set of customers. The routes obtained by the genetic algorithms are shorter than the routes obtained by the Greedy Algorithm (from 2\% to $14 \%$ ), but the computation time of the Genetic Algorithm is much higher than the computation time of the semi-greedy Algorithm. When solving real-life problems with an important number of customers, Genetic Algorithms need a big quantity of time.

Faster algorithms must be developed for complex problems such the problem presented above in realistic conditions, where is more important to analyse many configurations with suboptimal routes and clusters than less configurations with optimal routes and clustering, 
Genetic Algorithms can be used after the first set of iterations done by faster algorithms, when the most important variables have $b$ iteen decided (who is collaborating and the way they are collaborating) for optimizing the results obtained by the first group of algorithms in the clustering and routing phases.

Further developments are the following. Genetic algorithm should be programmed also for the clustering phase and for the whole problem solution, merging nodes from different clusters in the routes. When using genetic algorithms for both phases the complexity of the problem will increase, and the computation time needed for convergence will increase importantly. If the new genetic algorithm runs in reasonable times, the final step will be to use it for the collaborative 2E-VRP decision support, deciding the groups of operators that will collaborate and the way they will do it.

\section{References}

Baldacci, R., Mingozzi, A., Roberti, R., \& Calvo, R. W. (2013). An exact algorithm for the two-echelon capacitated vehicle routing problem. Operations Research, 61(2), 298-314.

Golden, B.L. (1988), Vehicle routing: methods and studies. Elsevier, Amsterdam, Studies in management science and systems, vol. 16.

Golden, B.L., Raghavan, S., Wasil, E.A. (2008). Vehicle routing: Latest advances and challenges, Kluwer, Boston, USA.

Gonzalez-Feliu, J. (2008), Models and Methods for the City Logistics - The Two-echelon Capacitated Vehicle Routing Problem. PhD. Thesis. Politecnico di Torino, Turin, Italy.

Gonzalez-Feliu, J., Morana, J. (2011). Collaborative transportation sharing: from theory to practice via a case study from France. In Yearwood, J.L. and Stranieri, A. (eds.). Technologies for Supporting Reasoning Communities and Collaborative Decision Making: Cooperative Approaches, Information Science Reference, pp. 252-271.

Gonzalez-Feliu, J., Salanova Grau, J.M., Morana, J. Ma, T.Y. (2013), Design and scenario assessment for collaborative logistics and freight transport systems, International Journal of Transport Economics, vol. 40, n. 2, pp. 207-240.

Gonzalez-Feliu, J., Salanova, J. (2012), Defining and evaluating collaborative urban freight distribution systems, Procedia Social and Behavioral Science, vol. 39, pp. 172-183.

Larranaga, P., Kuijpers, C. M. H., Murga, R. H., Inza, I., Dizdarevic, S. (1999). Genetic algorithms for the travelling salesman problem: A review of representations and operators. Artificial Intelligence Review, 13(2), 129-170.

Mancini, S., Gonzalez-Feliu, J., Crainic, T.G. (2014), Planning and Optimization Methods for Advanced Urban Logistics Systems at Tactical Level. In Gonzalez-Feliu J., Semet, F., Routhier, J.L. (eds), Sustainable urban logistics: concepts, methods and information systems, Springer, Heidelberg, pp. 145-164.

Toth, P., Vigo, D. (2002). The vehicle routing problem. SIAM Society for Industrial and Applied Mathematics, Philadelphia, USA. 